\title{
https://doi.org/10.46344/JBINO.2021.v10i02.14
}

\section{POTENTIAL ADVERSE EFFECTS OF VARIOUS DRUGS USED FOR THE TREATMENT OF ACUTE KIDNEY DISEASE}

\author{
Simranjeet Kaur* \& Gurkirat Singh \\ Faculty of Pharmaceutical Sciences, PCTE Group of Institutes, Baddowal- 141012, Ludhiana, Punjab, India
}

E-mail: $\underline{\text { simranjstl@gmail.com }}$

\begin{abstract}
Acute kidney disorders are common pathological conditions targeting kidneys with millions of cases worldwide. It is commonly seen in hospitalized patients, remarkably in critical patients. This paper provides a basic review of different kidney diseases known currently and the factors which lead to them. The drugs which are commonly used in the management of these conditions have been explained with the adverse effects commonly reported with their use. Various factors that lead to the use of these drugs and the conditions in which these drugs should be avoided are given. We will also review the prominent developed or under development novel treatment drugs that show profitable results in this disease.
\end{abstract}

KEYwORDS: Acute kidney diseases, oliguria, End Stage Kidney Disease, Diuretics 


\section{INTRODUCTION}

Acute kidney diseases or disorders (AKD) are a group of disorders that target normal structure and functions of the kidney or renal system as a result of which proper removal of waste from the blood doesn't take place. It is now well known that even slight abnormalities in the kidney structure and functions are linked with increased chances of developing complications in other organ systems and which may even lead to mortality.
Kidney diseases having a duration more than 3 months are termed chronic kidney diseases (CKD), while those lasting less than 3 months are termed acute kidney diseases (AKD)(1-3). Acute Kidney Injury $(A K I)$, previously known as Acute Renal Failure (ARF) is a subgroup of AKD in which otherwise healthy patient gets recovered within 7 days under favourable conditions. In some cases, it doesn't get recovered within 7 days and it gets converted into AKD.

\section{Classification of kidney disorders}

The KDIGO guidelines(4) for the definitions of kidney diseases and disorders are given below :

\begin{tabular}{|c|c|c|}
\hline & Functional Criteria & Structural Criteria \\
\hline AKI & $\begin{array}{l}\text { Increase in serum creatinine level by } 50 \% \text { within } 7 \text { days, or } \\
\text { increase in serum creatinine level by } 0.3 \mathrm{mg} / \mathrm{dL} \text { within } 2 \text { days, } \\
\text { or oliguria }\end{array}$ & No criteria \\
\hline CKD & GFR less than $60 \mathrm{~mL} / \mathrm{min}$ for more than 3 months & $\begin{array}{l}\text { Kidney damage for } \\
\text { more } \\
\text { than } 3 \text { months }\end{array}$ \\
\hline AKD & $\begin{array}{l}\text { AKI, or GFR less than } 60 \mathrm{~mL} / \mathrm{min} / 1.73 \mathrm{~m}^{2} \text { for less than } 3 \\
\text { months, or decrease in GFR by more than or equal to } 35 \% \text { or } \\
\text { increase in serum creatinine level by more than } 50 \% \text { for less } \\
\text { than } 3 \text { months }\end{array}$ & $\begin{array}{l}\text { Kidney damage for less } \\
\text { than } 3 \text { months }\end{array}$ \\
\hline NKD & $\begin{array}{l}\text { GFR more than or equal to } 60 \mathrm{~mL} / \mathrm{min} / 1.73 \mathrm{~m}^{2} \text {, stable serum } \\
\text { creatinine levels }\end{array}$ & No damage \\
\hline
\end{tabular}

The last stage of the CKD is termed as End Stage Renal Disorder (ESRD) or End Stage Kidney Disease(ESKD). At this stage, the patient cannot survive without dialysis or kidney transplant.

From the last few years, research on AKD without $A K I$ is being done. AKD without AKI has been added to the classification of kidney disorders and it has helped in the improved identification of patients who died or developed new CKD or ESRD.

$A K D$ without $A K I$ is quite common and is usually involved in long term bad outcomes. Norms for the detection and identification of AKD were first published in the KDIGO clinical practice guideline in 
2012, but still there is little data on the causes, treatment and clinical characteristics of the patients who developed AKD without AKI. The common conditions involved in AKD and $\mathrm{AKI}$ are crescentic glomerulonephritis and thrombotic microangiopathy. The probability of occurrence of acute tubular necrosis is twice among patients suffering from $A K I$ than those with AKD without AKI. The patients with AKD without AKI were more prone to acute tubulointerstitial nephritis than those with only AKD.(5)

\section{Causes of AKI}

AKI can be caused by factors classified into pre-renal, renal, and post-renal. (6) Pre-renal factors are the ones that lower blood supply to the kidney.

It can be due to the bleeding, vomiting or diarrhea, severe dehydration, heart failure, liver failure, sepsis, or due to the adverse effects of some medications.

Problems arising from the kidney itself are renal factors. E.g. Glomerulonephritis, inflammation and blockage in the blood vessels within kidneys(vasculitis)

Post-renal factors involve blockage of the urinary tract. E.g. Bladder, prostate or cervical cancer, enlarged prostate, kidney stones, blood clots in the urinary tract.

\section{Treatment of AKI}

Various types of drugs are used on an empirical basis for managing AKI and the complications that are involved. Several promising experimental therapies in animal models are awaiting human trials. As there is no specific data on the pathophysiology and treatment of AKD, these drugs can be equally used in managing AKD (Acute Kidney Disorder) until the data comes.
DIURETICS

Diuretics are commonly used to manage $A K I$ and AKD by increasing the urine output when there is less excretion of waste materials and water from the body.

Recent findings have revealed that diuretics are involved in the increased risk of AKI. The importance of diuretics in the preservation of renal medullary oxygenation has not been proved. Administration of higher cumulative diuretic dose during the dialysis period can lead to hypotension and thus increase mortality in a dose-dependent manner. (7) Diuretics must only be used in cases of fluid overdose and they are not recommended for the prevention of AKI.

Thiazide diuretics: There are various evidences proving that thiazides can cause renal structural changes. Clinical as well as population-based studies have reported that diuretics usage are not renal protective, but rather are involved in the acceleration of renal disease in the population. Hawkins and Houston published a paper demonstrating that thiazide usage leads to the increasing incidence of End Stage Renal Disease in the US.(8)

Loop diuretics: The data so far collected from different clinical trials do not justify the use of loop diuretics as treatment drugs in AKI. In the case of AKI prevention, LD may act protectively in some instances(contrast medium administration) as long as the drugs do not significantly decrease the intravascular volume and thus renal perfusion. (9) Loop Diuretics are not helpful for AKI treatment if we consider 
the safety of the kidney. LDs are prominently used to manage hyperkalemia in AKI patients.

Potassium-sparing diuretics: These can lead to hyperkalemia so these are not much used. Data collected from some papers suggest that spironolactone may prevent AKI after ischemia has occurred and may stop the progression to CKD.(10) Patients of elderly age with renal impairment if treated with potassiumsparing diuretics, renal failure may occur sometimes secondary to hypovolaemia, and nonsteroidal anti-inflammatory drugs (NSAIDs) may multiply the effect. (11)

\section{FLUIDS}

Intravenous fluids are generally needed in AKI to maintain urine output but it can also lead to fluid overdose which can cause edema. Various studies have suggested a connection between fluid overdose and mortality in patients having AKI. Fluid overdose may lead to sepsis by interfering in the gut barrier to microorganisms and it may also lead to edema in the renal tissues and may even lead to death in some cases. (12)

KDIGO suggests the usage of isotonic crystalloids like normal saline (NR) and lactated ringer (LR) solution instead of crystalloids like albumin, starches, etc. if safety is concerned. (13)

\section{VASOPRESSOR AGENTS}

These agents can be used in the critical cases of vasomotor shocks for the purpose of volume resuscitations to increase renal perfusion.

Dopamine stimulates adrenergic and dopaminergic receptors. Lower doses (0.5-3.0 $\mathrm{mcg} / \mathrm{kg} / \mathrm{min})$ primarily stimulate dopaminergic receptors, which produces renal and mesenteric vasodilation.(14)
Some studies even denied the benefits of low dose dopamine in AKI and concluded that dopamine even worsens the condition. $(14,15)$ Other potential complications of dopamine use include cardiac arrhythmias, myocardial ischemia, and intestinal ischemia, dyspnea, vomiting, anxiety, Increased intraocular pressure; dilated pupils.

Norepinephrine is a safer alternative as compared to dopamine because various studies have found that chances of occurrence of adverse effects are more in AKI patients treated with dopamine than which are treated with norepinephrine. While in the case of septic induced AKI, norepinephrine use lead to higher mortality in patients requiring dialysis. (16)

\section{VASODILATORS}

If increased blood pressure is to be controlled in AKI, vasodilators are preferred over ARBS, ACE inhibitors due to less adverse effects. ARBs, ACE inhibitors are nephrotoxic drugs with many severe adverse effects on renal tissues. (17-19)

Fenoldopam is a great vasodilator which usually acts on the dopamine receptorspecific agonist. It is 6 times more potent than dopamine in producing renal vasodilation. (20) It increases diuresis and has minimal adrenergic effects. Fenoldopam is indicated for the treatment of severe hypertension, including patients with renal compromise but it is also involved in increase serum creatinine levels in some patients. Hypotension is usually observed which can be managed by giving calculated doses or administering vasopressors. (21)

\section{ANTIOXIDANTS}

$\mathrm{N}$-acetylcysteine (NAC) is a quite useful 
drug in avoiding contrast-induced AKI. It prevents nephropathic conditions by acting as an antioxidant to target free radicals. It also leads to the proper endothelium-derived vasodilation. It is a precursor of glutathione, the antioxidant which is made by our body. (22) But in some studies, NAC just reduced the severity of the AKI and didn't have any major benefit in the prevention of AKI. (23) Optimal therapeutic dose has not been determined for this drug. Although, this can be used in prophylaxis of $\mathrm{Cl}-\mathrm{AKI}$ but it is not advised to be used for the management of $\mathrm{AKI}$, as it has been proved that prolonged use of NAC produced adverse effects as it significantly dampened the body's internal damage protective and antioxidant mechanisms as a result of which, progression to CKD can also occur. (24)

\section{Calcium Channel Blockers}

Various animal models have accepted the use of CCBs in AKI but in human trials, it has shown both positive and negative effects. (25) The effects of calcium channel blockers are believed to be mediated through vasodilation, and they are increasingly used to enhance the function of transplanted kidneys. Nifedipine relaxes smooth muscle and produces vasodilation, which, in turn, improves blood flow and oxygen delivery. some more research is being done on these drugs. Hypotension is the common side effect of CCBs but hypotension can lead to renal hypoperfusion indicating more risk of prerenal AKI.

\section{ANTISEPTICS}

Septic shock commonly leads to AKI. Chances of AKI vary from 12 to $40 \%$ and may be as high as $65 \%$ in patients suffering from sepsis. Around $48 \%$ of AKI cases in Intensive Care Unit (ICU) patients happened due to sepsis(26). So sepsis is the most common cause of AKI in ICU patients. Non-septic AKI is not much serious as compared to AKI developed from sepsis. There are various differences in the underlying causes and treatment patterns of septic AKI and non-septic AKI.(27)

In the treatment of septic AKI, early administration of antibiotics is very helpful. Various other measures to prevent hypotension and maintain fluid volume should be used.

Inappropriate use of antibiotics may direct to treatment failure and increased mortality rate. It can even lead to the development of antibiotic resistance. Many of the antibiotics are nephrotoxic, so it becomes more difficult to find a good candidate.

In various cases, doxycycline has been used as a safer alternative. It is a broadspectrum antibiotic of tetracycline class. In spite of being a tetracycline drug, toxicity is not usually observed because of its extrarenal mode of excretion. However, it is found to be causing some problems in the extrarenal modes of excretion after a regular use. (28)

\section{Novel Treatment Drugs}

\section{ANTI-APOPTOSIS/NECROSIS AGENTS}

\section{Caspase Inhibitors}

It has been proved that the caspases are the proteases that indulge in the initiation 
and execution of apoptosis. Nonselective and selective caspase inhibitors effectively managed renal injury in ischemia or endotoxemia-induced AKI when administered before or at the time of injury.(30) There are various clinical trials regarding the safety and efficacy of caspase inhibitors and still, no adverse effects have been detected in AKI treatment.

\section{Minocycline}

Minocycline comes under the class of second-generation tetracycline antibiotics. It produces antiapoptotic and anti-inflammatory effects. When it was administered 36 hours before renal ischemia, reduction in tubular cell apoptosis and mitochondrial release of cytochrome c, p53, and Bax was seen. (31) It has shown good capability in reducing kidney inflammation and microvascular permeability. (32)

\section{Guanosine and Pifithrin-a (p53 Inhibitor)}

Exogenous administration of guanosine helped to recover GTP which reduced renal tubular cell apoptosis. (33) Pifithrin-a which is a novel p53 inhibitor also acts as a renal protective agent by significantly decreasing tubulo cellular apoptosis. (34) Huge expectations are on this drug as it is also nearing clinical trials of cancer.

\section{FREE RADICAL SCAVENGERS}

\section{Deferoxamine}

Reactive oxygen species are usually formed in the early step of AKI.(35) Deferoxamine is well known for its ironchelating properties. Various studies have found it beneficial in iron-mediated oxidation stress. $(36,37)$ It is widely used to remove excess iron from the body in cases of anemia and thalassemia and also to treat iron poisoning in children.

Any adverse effects of this drug concerning $\mathrm{AKI}$ are not seen. However, this drug shouldn't be used for the prophylaxis of $\mathrm{AKI}$ as it can lead to renal injury on regular use without proper dose checks. Various studies are being done to find more data on this drug molecule.

\section{GROWTH FACTORS}

\section{Recombinant Erythropoietin}

It has shown quite good effects in ischemia induced renal injuries. (38) It has anti-apoptotic as well as antiinflammatory actions which have been used in various studies for AKI management. Good results were visible when it was used in the management of cisplatin-induced AKI as there was a noticeable reduction in apoptosis and necrosis. (39) On the other hand, there are few adverse effects also like thrombosis, tumor growth, and hypertension if high doses are given. Being an ESA,

it has been used in managing anemia in patients with CKD, but its use in the management of anemia in $\mathrm{AKI}$ is debatable. (40)

\section{DISCUSSION}

Diuretics can only be used in cases when there is an urgent need to manage excess ECF volume. High doses of diuretics can potentiate adverse events. LDs are preferred in terms of efficacy to lower fluid volume. As hyperkalemia is generally seen in $\mathrm{AKI}$, the use of potassium-sparing diuretics is not advised. Thiazides are least preferred in the case of AKI. In the case of IV fluids, the use of isotonic crystalloids is advised but fluid overdose must be avoided. Improvement of renal perfusion can be achieved by 
using vasopressors. Norepinephrine is more preferred in terms of safety but it has not provided many benefits in AKI patients. If high blood pressure is making the situation unpleasant, vasodilators and CCBs are indicated. CCBs must be used carefully as their prolonged use is linked with AKI propagation. Fenoldopam is a very capable vasopressor drug with minimum adverse effects. Sepsis is the most common cause of AKI among ICU patients.

As an antibiotic, doxycycline offers less adverse effects but its dose must be maintained.

Various modern treatment methods and drugs have been developed and their clinical trials are being done. Antiapoptotic agents, free radical scavengers, growth factors, recombinant proteins are just a few of them. Managing inflammatory responses and renal necrosis is the most important part of AKI management. In such cases, antiapoptotic agents have good applications especially caspase inhibitors with minor adverse effects.

AKI occurs through multiple pathways, so targeting only one pathway or just treating arising situations is not enough. Various techniques like combination drug therapy or drug showing good effects in multiple pathways are needed to be discovered.

\section{CONCLUSION}

Finally, it may be concluded that almost all of the drugs are accompanied by adverse effects in treatment. Novel drugs are an exception as they are showing good results with minimal adverse effects in AKI. New drugs with more targetspecific effects and negligible adverse events are need of the hour. Due to the Covid-19 crisis, progress in research and clinical trials of drugs for $\mathrm{AKI}$ and other diseases has slowed down as all of the scientists are working to find a cure for Covid-19 but it will resume soon when this pandemic will end.

\section{REFERENCES}

AS L, PE de J, J C, M EN, BC A, KM, et al. The definition, classification, and prognosis of chronic kidney disease: a KDIGO Controversies Conference report. Kidney Int [Internet]. 2011;80(1):17-28. Available from: http://www.ncbi.nlm.nih.gov/pubmed/21 150873

Levin A, Stevens PE, Bilous RW, Coresh J, De Francisco ALM, De Jong PE, et al. Kidney disease: Improving global outcomes (KDIGO) CKD work group. KDIGO 2012 clinical practice guideline for the evaluation and management of chronic kidney disease [Internet]. Vol. 3, Kidney International Supplements. Nature Publishing Group; 2013 [cited 2020 Oct 2]. p. 1-150. Available from: https://jhu.pure.elsevier.com/en/publicati ons/kidney-disease-improving-globaloutcomes-kdigo-ckd-work-group-kdi-4

Kellum JA, Lameire N, Aspelin P, Barsoum RS, Burdmann EA, Goldstein SL, et al. Kidney disease: Improving global outcomes (KDIGO) acute kidney injury work group. KDIGO clinical practice guideline for acute kidney injury [Internet]. Vol. 2, Kidney International Supplements. Nature Publishing Group; 2012 [cited 2020 Oct 2]. p. 1-138. Available from: https://experts.umn.edu/en/publications/ 
kidney-disease-improving-globaloutcomes-kdigo-acute-kidney-injur

Levey AS, Levin A, Kellum JA. Definition and classification of kidney diseases [Internet]. Vol. 61, American Journal of Kidney Diseases. W.B. Saunders; 2013 [cited 2020 Oct 2]. p. 686-8. Available from:

http://dx.doi.org/10.1053/j.ajkd.2013.03.00 3

James MT, Levey AS, Tonelli M, Tan Z, Barry R, Pannu $N$, et al. Incidence and Prognosis of Acute Kidney Diseases and Disorders Using an Integrated Approach to Laboratory Measurements in a Universal Health Care System. JAMA Netw open [Internet]. 2019 Apr 5 [cited 2020 Oct 2];2(4):e191795. Available from: https://jamanetwork.com/

Makris K, Spanou L. Acute Kidney Injury: Definition, Pathophysiology and Clinical Phenotypes. Clin Biochem Rev [Internet]. 2016 May [cited 2020 Oct 2];37(2):85-98. Available from: http://www.ncbi.nlm.nih.gov/pubmed/28 303073

Ejaz AA, Mohandas R. Are diuretics harmful in the management of acute kidney injury? [Internet]. Vol. 23, Current Opinion in Nephrology and Hypertension. Curr Opin Nephrol Hypertens; 2014 [cited 2020 Oct 3]. p. 155-60. Available from: https://pubmed.ncbi.nlm.nih.gov/243897 $31 /$

Hawkins RG, Houston MC. Is populationwide diuretic use directly associated with the incidence of end-stage renal disease in the United States? A hypothesis. Am J Hypertens [Internet]. 2005 Jun [cited 2020
Oct 3];18(6):744-9. Available from: https://pubmed.ncbi.nlm.nih.gov/159257 29/

Marenzi G, Ferrari C, Marana I, Assanelli E, De Metrio M, Teruzzi $G$, et al. Prevention of contrast nephropathy by furosemide with matched hydration: The MYTHOS (induced diuresis with matched hydration compared to standard hydration for contrast induced nephropathy prevention) trial. JACC Cardiovasc Interv [Internet]. 2012 Jan [cited 2020 Oct 3]:5(1):90-7. Available from: https://pubmed.ncbi.nlm.nih.gov/222301 54/

Barrera-Chimal J, Pérez-Villalva R, Rodríguez-Romo R, Reyna J, Uribe N, Gamba G, et al. Spironolactone prevents chronic kidney disease caused by ischemic acute kidney injury. Kidney Int. 2013 Jan 1;83(1):93-103.

Renal failure with potassium-sparing diuretics - PubMed [Internet]. [cited 2020 Oct 3]. Available from: https://pubmed.ncbi.nlm.nih.gov/386197 3/

Butcher BW, Liu KD. Fluid overload in AKI. Curr Opin Crit Care [Internet]. 2012 Dec [cited 2020 Oct 3];18(6):593-8. Available from: http://journals.Iww.com/00075198201212000-00004

Okusa MD, Davenport A. Reading between the (guide)lines - The KDIGO practice guideline on acute kidney injury in the individual patient [Internet]. Vol. 85, Kidney International. Nature Publishing Group; 2014 [cited 2020 Oct 3]. p. 39-48. Available from: http://www.kidneyinternational.org 
Marinosci GZ, De Robertis E, De Benedictis G, Piazza O. Dopamine Use in Intensive Care: Are We Ready to Turn it Down? Transl Med @ UniSa [Internet]. 2012 Sep [cited 2020 Oct 4];4(11):90-4. Available from:

http://www.ncbi.nlm.nih.gov/pubmed/23 905068

Lauschke A, Teichgräber U, Frei U, Eckardt KU. "Low-dose" dopamine worsens renal perfusion in patients with acute renal failure. Kidney Int [Internet]. 2006 May 1 [cited 2020 Oct 4];69(9):1669-74. Available from: http://www.kidneyinternational.org

Chen Y-Y, Wu V-C, Huang W-C, Yeh Y-C, Wu M-S, Huang C-C, et al. Norepinephrine Administration is Associated with Higher Mortality in Dialysis Requiring Acute Kidney Injury Patients with Septic Shock. J Clin Med [Internet]. 2018 Sep 12 [cited 2020 Oct 4];7(9):274. Available from: /pmc/articles/PMC6162856/2report=abstr act

Tomlinson LA, Abel GA, Chaudhry AN, Tomson CR, Wilkinson IB, Roland MO, et al. ACE Inhibitor and Angiotensin Receptor-II Antagonist Prescribing and Hospital Admissions with Acute Kidney Injury: A Longitudinal Ecological Study. Berthold HK, editor. PLoS One [Internet]. 2013 Nov 6 [cited 2020 Oct 4];8(11):e78465. Available from: https://dx.plos.org/10.1371/journal.pone.0 078465

Sprenger-Mähr H, Zitt E, Lhotta K. Acute Kidney Injury Treated with Dialysis outside the Intensive Care Unit: A Retrospective
Observational Single-Center Study. Andò G, editor. PLoS One [Internet]. 2016 Sep 27 [cited 2020 Oct 4];11(9):e0163512. Available from: https://dx.plos.org/10.1371/journal.pone.0 163512

Joannidis $M$, Druml W, Forni LG, Groeneveld ABJ, Honore PM, Hoste E, et al. Prevention of acute kidney injury and protection of renal function in the intensive care unit: update 2017: Expert opinion of the Working Group on Prevention, AKI section, European Society of Intensive Care Medicine. Intensive Care Med [Internet]. 2017 Jun 1 [cited 2020 Oct 4];43(6):730-49. Available from: https://link.springer.com/article/10.1007/s 00134-017-4832-y

Hunter DW, Chamsuddin A, Bjarnason $H$, Kowalik K. Preventing contrast-induced nephropathy with fenoldopam [Internet]. Vol. 4, Techniques in Vascular and Interventional Radiology. Elsevier; 2001 [cited 2020 Oct 4]. p. 53-6. Available from:

http://www.techvir.com/article/S1089251 605800071/fulltext

Gillies MA, Kakar V, Parker RJ, Honoré PM, Ostermann M. Fenoldopam to prevent acute kidney injury after major surgery-a systematic review and meta-analysis. Crit Care [Internet]. 2015 Dec 25 [cited 2020 Oct 4];19(1). Available from: https://pubmed.ncbi.nlm.nih.gov/267033 29/

Huang JW, Clarkin OJ, McCudden C, Akbari A, Chow BJW, Shabana W, et al. The Effect of $\mathrm{N}$-Acetylcysteine on Creatinine Measurement: Protocol for a Systematic Review. Can J Kidney Heal Dis 
[Internet]. 2018 Sep 1 [cited 2020 Oct 4];5. Available from: /pmc/articles/PMC6156188/?report=abstr act

Pannu N, Manns B, Lee $H$, Tonelli $M$. Systematic review of the impact of $\mathrm{N}$ acetylcysteine on contrast nephropathy. Kidney Int [Internet]. 2004 Apr 1 [cited 2020 Oct 4];65(4):1366-74. Available from: http://www.kidneyinternational.org/article/S00852538154984 $5 \mathrm{X} /$ fulltext

Small DM, Sanchez WY, Roy SF, Morais C, Brooks HL, Coombes JS, et al. N-acetylcysteine increases cellular dysfunction in progressive chronic kidney damage after acute kidney injury by dampening endogenous antioxidant responses. Am J Physiol - Ren Physiol [Internet]. 2018 [cited 2020 Oct 4];314(5):F956-68. Available from:

https://journals.physiology.org/doi/abs/10 .1152 /ajprenal.00057.2017

Diamond JR, Cheung JY, Fang LST. Nifedipine-induced renal dysfunction. Alterations in renal hemodynamics. Am J Med [Internet]. 1984 Nov 1 [cited 2020 Oct 4];77(5):905-9. Available from: http://www.amjmed.com/article/0002934 384905400/fulltext

Majumdar A. Sepsis-induced acute kidney injury [Internet]. Vol. 14, Indian Journal of Critical Care Medicine. Indian Society of Critical Care Medicine; 2010 [cited 2020 Oct 4]. p. 14-21. Available from:

/pmc/articles/PMC2888325/2report=abstr act
Saotome T, May C, Bellomo R. Pathophysiology of septic acute kidney injury: What do we really know? [Internet]. Vol. 36, Critical Care Medicine. Lippincott Williams and Wilkins; 2008 [cited 2020 Oct 4]. Available from: https://pubmed.ncbi.nlm.nih.gov/183821 94/

Orr LH, Rudisill E, Brodkin R, Hamilton RW. Exacerbation of Renal Failure Associated With Doxycycline. Arch Intern Med [Internet]. 1978 May 1 [cited 2020 Oct 4];138(5):793-4. Available from: https://jamanetwork.com/journals/jamain ternalmedicine/fullarticle/587969

Havasi A, Borkan SC. Apoptosis and acute kidney injury [Internet]. Vol. 80, Kidney International. Nature Publishing Group; 2011 [cited 2020 Oct 4]. p. 29-40. Available from: /pmc/articles/PMC 4625984/?report=abstr act

Daemen MARC, Van't Veer C, Denecker G, Heemskerk VH, Wolfs TGAM, Clauss $M$, et al. Inhibition of apoptosis induced by ischemia-reperfusion prevents inflammation. J Clin Invest [Internet]. 1999 [cited 2020 Oct 4];104(5):541-9. Available from:

https://pubmed.ncbi.nlm.nih.gov/104877 68/

Kelly KJ, Sutton TA, Weathered N, Ray N, Caldwell EJ, Plotkin Z, et al. Minocycline inhibits apoptosis and inflammation in a rat model of ischemic renal injury. Am J Physiol - Ren Physiol [Internet]. 2004 Oct [cited 2020 Oct 4];287(4 56-4):760-6. Available from: http://www.ajprenal.org

Wan L, Bagshaw SM, Langenberg C, Sutton TA, Kelly KJ, Mang HE, Plotkin Z, 2021 March Edition | www.jbino.com | Innovative Association 
Sandoval RM, Dagher PC. Minocycline reduces renal microvascular leakage in a rat model of ischemic renal injury. Am J Physiol - Ren Physiol [Internet]. 2005 Jan [cited 2020 Oct 4];288(1 57-1). Available from:

https://pubmed.ncbi.nlm.nih.gov/153534 $01 /$

Kelly KJ, Plotkin Z, Dagher PC. Guanosine supplementation reduces apoptosis and protects renal function in the setting of ischemic injury. J Clin Invest [Internet]. 2001 [cited 2020 Oct 4];108(9):1291-8. Available from: https://pubmed.ncbi.nlm.nih.gov/116965 73/

Kelly KJ, Plotkin Z, Vulgamott SL, Dagher PC. P53 mediates the apoptotic response to GTP depletion after renal ischemiareperfusion: Protective role of a p53 inhibitor. J Am Soc Nephrol [Internet]. 2003 Jan 1 [cited 2020 Oct 4];14(1):128$38 . \quad$ Available from: https://jasn.asnjournals.org/content/14/1/ 128

Baliga R, Ueda N, Walker PD, Shah S V. Oxidant mechanisms in toxic acute renal failure. Drug Metab Rev [Internet]. 1999 [cited 2020 Oct 4];31(4):971-97. Available from:

https://pubmed.ncbi.nlm.nih.gov/105755 $56 /$

Baliga R, Zhang Z, Baliga M, Ueda N, Shah $S$ V. In vitro and in vivo evidence suggesting a role for iron in cisplatininduced nephrotoxicity. Kidney Int [Internet]. 1998 [cited 2020 Oct
4]:53(2):394-401. Available from: https://pubmed.ncbi.nlm.nih.gov/946109 8/

Walker PD, Shah S V. Evidence suggesting a role for hydroxyl radical in gentamicininduced acute renal failure in rats. $J$ Clin Invest [Internet]. 1988 [cited 2020 Oct 4]:81(2):334-41. Available from: https://pubmed.ncbi.nlm.nih.gov/312351 8/

Vesey DA, Cheung C, Pat B, Endre Z, Gobé G, Johnson DW. Erythropoietin protects against ischaemic acute renal injury. Nephrol Dial Transplant [Internet]. 2004 Feb 1 [cited 2020 Oct 4];19(2):34855. Available from: https://academic.oup.com/ndt/article/1 9/2/348/1863835

Vaziri ND, Zhou XJ, Liao SY. Erythropoietin enhances recovery from cisplatininduced acute renal failure. Am J Physiol Ren Fluid Electrolyte Physiol [Internet]. 1994 [cited 2020 Oct 4];266(3 35-3). Available from: https://pubmed.ncbi.nlm.nih.gov/816078 3/

Erythropoietin Role in Acute Kidney Injury | Clinical Research Trial Listing ( Anemia Renal ) ( NCT03401710) [Internet]. [cited 2020 Oct 4]. Available from: https://www.centerwatch.com/clinicaltrials/listings/192906/anemia-renalerythropoietin-role-acute-kidney/ 